\title{
Tamsulosin Monotherapy versus Combination Therapy with Antibiotics or Anti-Inflammatory Agents in the Treatment of Chronic Pelvic Pain Syndrome
} \author{
Geun Soo Kong ${ }^{4}$, Dong Woo Kim ${ }^{5}$, Won Yeol Cho \\ Department of Urology, Dong-A University College of Medicine, Busan; \\ ${ }^{1}$ Department of Urology, Dongnam Inst. Radiological \& Medical Sciences, Busan; \\ ${ }^{2}$ Department of Urology, Youngdo Hospital, Busan; \\ ${ }^{3}$ Department of Urology, Maryknoll Hoapital, Busan; \\ ${ }^{4}$ Department of Urology, Bumin Hospital, Busan; \\ ${ }^{5}$ Department of Urology, Dong Rae Bong Seng Hospital, Busan, Korea
}

Tae Hyo Kim, Ki Soo Lee ${ }^{1}$, Jeong Ho Kim, Joon Yeop Jee, Young Eun Seo, Dong Won Choi², Yeul Geun Sung ${ }^{3}$,

Purpose: Chronic pelvic pain syndrome (CPPS) is treated by use of various protocols. We compared tamsulosin monotherapy with tamsulosin in combination with antibiotics or anti-inflammatory agents and evaluated the efficacy of these treatments in patients with CPPS.

Methods: Patients $(n=107)$ who were younger than 55 years and diagnosed with CPPS were randomly assigned to treatment with tamsulosin at $0.2 \mathrm{mg}$ (group A), tamsulosin at $0.2 \mathrm{mg}$ plus anti-inflammatory drugs (group B) or tamsulosin at $0.2 \mathrm{mg}$ plus antibiotics (group C) daily. We applied the National Institutes of Health-Chronic Prostatitis Symptom Index (NIH-CPSI) and the International Prostate Symptom Score (IPSS) to evaluate 100 patients who were treated for 12 weeks (7 withdrew). Scores of the three groups were compared by analysis of variance and we also evaluated subscores, which included pain, voiding and quality of life (QoL).

Results: All three groups showed statistically significant decreases in NIH-CPSI score, IPSS and subscore scores $(\mathrm{P}<0.05)$. There were no statistically significant differences between the groups except for the QoL domain of the IPSS (group A vs. C; P $<0.01$ ). Conclusions: Tamsulosin monotherapy for 12 weeks was effective for treating patients with CPPS, compared with combination therapy with antibiotics or anti-inflammatory drugs.

Keywords: Chronic Prostatitis with Chronic Pelvic Pain Syndrome; Tamsulosin

\section{INTRODUCTION}

Prostatitis is a common disease with a lifetime prevalence ranging from 5 to $16 \%$. In Korea, about 25\% of patients who visit a urology department for the treatment of genitourinary complaints exhibit this disease $[1,2]$. It decreases the quality of life (QoL) for patients as much as unstable angina and active Crohn's disease [3]. In 1968, Meares and Stamey published a landmark paper describing the differential diagnosis of prostatitis. Since then, many diagnostic tools and treatments have been investigated [4]. However, patients and clinicians still feel frustrated when the treatment of prostatitis fails because its etiology is unclear [5]. Only $10 \%$ of patients are diagnosed with bacterial prostatitis [6]. The other $90 \%$ of patients also have symptoms of prostatitis, including pelvic pain and urinary dysfunction. However, they are classified as having chronic nonbacterial prostati-
Corresponding author: Won Yeol Cho

Department of Urology, Dong-A University College of Medicine,

1 Dongdaesin-dong 3-ga, Seo-gu, Busan 602-715, Korea

Tel: +82-51-240-2816 / Fax: +82-51-253-0591 / E-mail: urogate@dau.ac.kr

Submitted: June 9, 2011 / Accepted after revision: June 20, 2011
This is an Open Access article distributed under the terms of the Creative Commons Attribution Non-Commercial License (http://creativecommons.org/licenses/by-nc/3.0/) which permits unrestricted non-commercial use, distribution, and reproduction in any medium, provided the original work is properly cited. 
tis/chronic pelvic pain syndrome (CP/CPPS), National Institutes of Health (NIH) category III, because of an absence of leukocytes or bacteria in the prostatic fluid [5].

The symptoms of CP/CPPS are similar to those of benign prostatic hyperplasia (BPH) and investigators have hypothesized that drugs effective for BPH might help some patients with CP/CPPS. Several studies have demonstrated that $\alpha$-blockers improve the symptoms of CP/CPPS although the mechanisms by which the pain was relieved were unclear.

Some studies have demonstrated no better effects than combined therapy during 8 weeks.

We conducted a prospective, randomized study to assess the efficacy of tamsulosin a-blocker monotherapy for CP/CPPS compared with combined therapy including antibiotics or antiinflammatory drugs for 12 weeks. We evaluated outcomes by using the NIH-Chronic Prostatitis Symptom Index (NIH-CPSI) score and the International Prostate Symptom Score (IPSS).

\section{MATERIALS AND METHODS}

The study had a randomized, multicenter, parallel, prospective design. It was conducted at six hospitals in Busan, Korea. Patients aged younger than 55 years who were diagnosed with CP/CPPS were screened and then asked to participate in a prospective prostatitis treatment study running from March 1, 2008 to February 28,2009 . Physical examinations, standard microbiological cultures and microscopic analysis of urine, transrectal ultrasonography (TRUS) and serum prostate-specific antigen (PSA) measurements were used for the diagnosis of CP/CPPS. Patients were included if they had pain or discomfort in the pelvic region for at least 3 months, a total score of at least 12 on the NIH-CPSI and anticipated improvement of symptoms with therapy. Based on the number of leukocytes in the expressed prostatic secretions or post-prostatic massage voided urine, the patients were categorized as having NIH category IIIA (leukocyte count $>10$ high power field [HPF]) and IIIB (leukocyte count $<10$ HPF). Patients with a urinary tract infection determined by urine study, hypoechoic lesions on TRUS, a serum PSA level of $3 \mathrm{ng} /$ $\mathrm{dL}$ or more or a history of disease that could have affected the results of this study were excluded. Finally, 107 patients who agreed to participate were randomly assigned to three groups. All patients were treated with tamsulosin $0.2 \mathrm{mg}$ once daily. Group A received tamsulosin alone. Group B also received diclofenac $50 \mathrm{mg}$ twice daily, and group $\mathrm{C}$ also received ciprofloxacin $500 \mathrm{mg}$ twice daily. We did not have placebo group, be- cause the effects of each drugs such as a-blocker, antibiotics and non-steroidal anti-inflammatory drugs were widely known to the standard drug for CP/CPPS treatment. All patients underwent 2 weeks of washout time from the first visit. Patients were enrolled to subgroup by the table of random sampling digit in each medical center. Patients were subjected to urine flow and residual urine volume measurements and completed questionnaires on the NIH-CPSI and the IPSS immediately after the washout time. In screening visit, seven patients dropped out, so the NIH-CPSI and IPSS were readministered to 100 patients who were treated for 12 weeks. We compared the baseline scores with post-treatment scores to analyze the efficacy of each treatment. Differences between pre- and post-treatment scores of the three groups were compared by using analysis of variance (ANOVA). Subjective subscore including pain, voiding and QoL were also recorded. We used SPSS ver. 12 (SPSS Inc., Chicago, IL, USA) for the statistical analysis.

\section{RESULTS}

Of the 107 patients who agreed to participate in this study, 7 withdrew. Five patients were eliminated from the study because they had taken other anti-inflammatory drugs or antibiotics while the study was in progress. Two patients opted for transurethral resection of the prostate. The three treatment groups were statistically similar in baseline characteristics (Table 1).

Table 2 shows the difference between pre- and post-treatment scores. The baseline scores did not show statistically significant differences between the three groups. After 12 weeks of treatment, the tamsulosin monotherapy group (group A) had a significant reduction in mean NIH-CPSI total score (23.6 \pm 5.5 at baseline to $8.6 \pm 4.1$ at week 12) and NIH-CPSI subscores (pain, voiding and QoL), as did groups B (23.9 \pm 5.9 to $7.7 \pm 4.9)$ and $\mathrm{C}(23.2 \pm 5.5$ to $8.1 \pm 4.2)$ (both $\mathrm{P}<0.05$; Table 2$)$. The total scores

Table 1. Comparison of baseline characteristics of patients

\begin{tabular}{|c|c|c|c|}
\hline Characteristics & \multicolumn{3}{|c|}{ Group A Group B Group C } \\
\hline No. of patients & 40 & 32 & 28 \\
\hline Mean age $(y r)$ & 45.7 & 46.5 & 46.1 \\
\hline Mean prostate volume $\left(\mathrm{cm}^{3}\right)$ & 30.1 & 29.7 & 29.4 \\
\hline Mean serum PSA level (ng/mL) & 0.97 & 0.95 & 1.00 \\
\hline Mean maximal urine flow rate $(\mathrm{mL} / \mathrm{sec})$ & 18.8 & 19.39 & 18.5 \\
\hline Mean residual urine volume $(\mathrm{mL})$ & 21.6 & 23.8 & 23.3 \\
\hline
\end{tabular}

PSA, prostate-specific antigen. 
Table 2. Comparison of baseline scores with post-treatment scores (NIH-CPSI)

\begin{tabular}{|c|c|c|c|c|c|c|c|c|c|}
\hline \multirow{3}{*}{ Group } & \multicolumn{8}{|c|}{ NIH-CPSI } & \multirow{3}{*}{ P-value } \\
\hline & \multicolumn{4}{|c|}{ Baseline } & \multicolumn{4}{|c|}{ Three months later } & \\
\hline & Total & Pain $^{\text {a) }}$ & Voiding $^{\text {a) }}$ & QoL $^{\text {a) }}$ & Total & Pain $^{\text {a) }}$ & Voiding $^{\text {a) }}$ & QoL $^{\text {a) }}$ & \\
\hline A & $23.6 \pm 5.5$ & $11.4 \pm 3.9$ & $4.2 \pm 2.0$ & $8.1 \pm 2.3$ & $8.6 \pm 4.1$ & $4.0 \pm 3.2$ & $1.6 \pm 1.5$ & $3 \pm 1.98$ & $<0.05$ \\
\hline B & $23.9 \pm 5.9$ & $11.6 \pm 3.5$ & $4.0 \pm 2.1$ & $7.9 \pm 2.6$ & $7.7 \pm 4.9$ & $3.4 \pm 2.7$ & $1.5 \pm 1.2$ & $2.81 \pm 1.75$ & $<0.05$ \\
\hline C & $23.17 \pm 5.5$ & $10.9 \pm 4.0$ & $3.7 \pm 1.5$ & $8.5 \pm 2.1$ & $8.1 \pm 4.2$ & $3.7 \pm 2.8$ & $1.7 \pm 1.0$ & $2.8 \pm 1.5$ & $<0.05$ \\
\hline
\end{tabular}

NIH-CPSI, National Institutes of Health-Chronic Prostatitis Symptom Index; QoL, quality of life.

${ }^{a)}$ Subscore.

Table 3. Comparison of baseline scores with post-treatment scores (IPSS)

\begin{tabular}{|c|c|c|c|c|c|c|c|c|c|}
\hline \multirow{3}{*}{ Group } & \multicolumn{8}{|c|}{ IPSS } & \multirow{3}{*}{ P-value } \\
\hline & \multicolumn{4}{|c|}{ Baseline } & \multicolumn{4}{|c|}{ Three months later } & \\
\hline & Total & Voidinga) $^{\text {a) }}$ & Storage $^{\text {a) }}$ & $\mathrm{QoL}^{\mathrm{a})}$ & Total & Voiding ${ }^{\text {a) }}$ & Storage ${ }^{a)}$ & QoL $^{\text {a) }}$ & \\
\hline A & $14.3 \pm 6.21$ & $4.9 \pm 3.1$ & $9.4 \pm 3.8$ & $4.0 \pm 0.7$ & $7.2 \pm 3.8$ & $2.7 \pm 2.0$ & $4.5 \pm 2.4$ & $2.1 \pm 0.6$ & $<0.05$ \\
\hline B & $13.3 \pm 6.6$ & $4.9 \pm 3.8$ & $8.4 \pm 4.3$ & $4.0 \pm 0.9$ & $5.9 \pm 3.4$ & $2.1 \pm 1.7$ & $3.8 \pm 2.3$ & $1.9 \pm 0.7$ & $<0.05$ \\
\hline $\mathrm{C}$ & $12.4 \pm 5.4$ & $3.7 \pm 2.8$ & $8.7 \pm 3.3$ & $3.8 \pm 0.7$ & $6.1 \pm 3.6$ & $1.8 \pm 1.5$ & $4.3 \pm 2.5$ & $1.7 \pm 0.6$ & $<0.05$ \\
\hline
\end{tabular}

IPSS, International Prostate Symptom Score; QoL, quality of life.

${ }^{a)}$ Subscore.

Table 4. Comparative analysis of each group by analysis of variance (ANOVA)

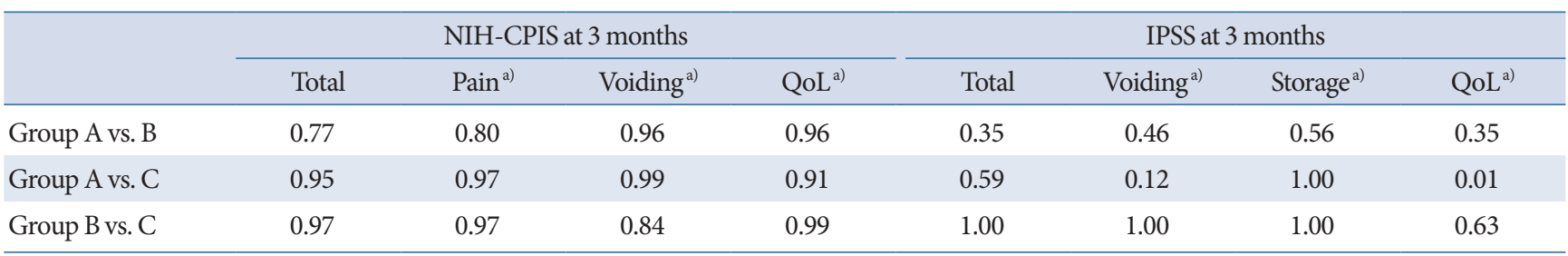

NIH-CPSI, National Institutes of Health-Chronic Prostatitis Symptom Index; International Prostate Symptom Score; QoL, quality of life.

${ }^{\text {a) }}$ Subscore.

and the three subscores of the IPSS (voiding, storage and QoL) also decreased in all three groups (group A, $14.3 \pm 6.2$ to $7.2 \pm 3.8$; group B, $13.3 \pm 6.6$ to $5.9 \pm 3.4$; group C, $12.4 \pm 5.4$ to $6.1 \pm 3.6$ ) (all $\mathrm{P}<0.05$; Table 3 ). The data of the three groups showed sufficient effects of treatment for patients with CP/CPPS. There were no statistically significant differences between groups shown by ANOVA, except for the QoL subscore of the IPSS (group A vs. C; $\mathrm{P}<0.01$; Table 4).

\section{DISCUSSION}

The etiology of CP/CPPS is unknown but can include microorganisms, viruses, autoimmune disease, cytokines or reflux of urine to the prostate [7]. Many treatments have been investigat- ed in pilot studies. These have included antibiotics, $a$-blockers, nonsteroidal anti-inflammatory agents, pentosan sulfate, allopurinol, quercetin, finasteride, weekly ejaculation, transurethral and subtotal prostatic resection, transurethral incision of the prostate, balloon dilatation, hyperthermia, transurethral needle ablation and radical prostatectomy [4]. The latest fashion for treating patients with CP/CPPS is the combination therapy of agents termed the "three As" antibiotics, nonsteroidal anti-inflammatory drugs and $\alpha_{1}$-blockers [8]. Since Osborn et al. [9] reported that the symptoms of CPPS were improved in $48 \%$ of patients by treatment with phenoxybenzamine, the a-blockers have attracted attention as drugs of choice for patients with $\mathrm{CP}$ / CPPS. These drugs relieve lower urinary tract symptoms in patients with CP/CPPS because the $\alpha_{1}$-adrenergic blockade leads 
to smooth muscle relaxation in the bladder neck and prostate. This in turn permits increased urine flow and decreased urinary retention. How these agents relieve the pain associated with $\mathrm{CP} /$ CPPS is less clear. It probably involves antagonizing local and spinal $\alpha_{1 \mathrm{~A}}$ and $\alpha_{1 \mathrm{D}}$ receptors [10-12]. Cheah et al. [13] reported that 100 patients given 14 weeks of therapy with terazosine for CPPS had greater reductions in NIH-CPSI and IPSS scores than did a placebo group. Nickel et al. [14] reported that tamsulosin was superior to a placebo in providing symptomatic relief for patients with CP/CPPS, particularly among those with more severe symptoms. Mehik et al. [15] reported that 6 months of alfuzosin therapy for $\mathrm{CP} / \mathrm{CPPS}$ resulted in a statistically significant improvement in the NIH-CPSI compared with placebo, particularly in the pain domain, but the beneficial effect was only apparent only after several months of treatment and disappeared when treatment was discontinued. Here we evaluated the efficacy of tamsulosin, one of the "three As" drugs, for treating patients with $\mathrm{CP} / \mathrm{CPPS}$. We found that tamsulosin monotherapy was effective compared with combined therapy including antibiotics or anti-inflammatory drugs. Therefore, we can consider adopting tamsulosin monotherapy for treating patients with $\mathrm{CP} / \mathrm{CPPS}$. However, many investigators still insist that $\mathrm{CP} /$ CPPS is caused by pathogens, and other treatments including the use of muscle relaxants [16], anticholinergics, tricyclic antidepressants, finasteride [17], allopurinol [18], pentosan sulfate [19], phytotherapy [20], biofeedback [21], massage of the prostate [22], and regular ejaculation [23] have been advocated. Furthermore, some urologists assume that patients with bacterial prostatitis can be given a wrong diagnosis of nonbacterial prostatitis because cultures of their specimens are negative. This might arise because there are residual effects of previously taken antibiotics, individual differences in prostate massage skills for diagnosis, or prostatic duct obstruction caused by local inflammation. Therefore, it has been suggested that the optimal treatment plan for patients with CP/CPPS should be decided on only after evaluating the responses to antibiotics [22,24,25]. Nickel et al. [26] reported that 12 weeks of treatment with ofloxacin improved the symptoms in 50\% of patients with CP/ CPPS. A study by Youn et al. [27] compared antibiotic monotherapy with a combination therapy of antibiotics and an a-blocker. They observed sufficient efficacy with both treatments. Also, there have been many reports analyzing the efficacy of anti-inflammatory agents, for example refecoxib, a COX-2 inhibitor, by Nickel et al. [28] and Ibuprofen by Minnery and Getzenberg [29] Thus, tamsulosin monotherapy may not be sufficient to treat patients with CP/CPPS because the etiology of this disorder has not been revealed. Therefore further study about the etiology of CP/CPPS and the action mechanism of alpha blockers such as tamsulosin is necessary.

In conclusion, compared with combined therapies with antibiotics or anti-inflammatory drugs, tamsulosin monotherapy for 12 weeks was not inferior effects for treating patients with $\mathrm{CP} / \mathrm{CPPS}$. Tamsulosin monotherapy can be considered to treating CP/CPPS. Combination therapy with "three As" drug combinations and others are needed to maximize the effectiveness of treatment for CP/CPPS because there are some doubts about the etiology of this disorder. Therefore, we need further studies that adjust the methods of treatment to the clinical characteristics of individual patients.

\section{CONFLICT OF INTEREST}

No potential conflict of interest relevant to this article was reported.

\section{REFERRENCES}

1. Collins MM, Stafford RS, O'Leary MP, Barry MJ. How common is prostatitis? A national survey of physician visits. J Urol 1998;159: 1224-8.

2. Yoo YN. Prostatitis. Korean J Urol 1994;35:575-85.

3. Wenninger K, Heiman JR, Rothman I, Berghuis JP, Berger RE. Sickness impact of chronic nonbacterial prostatitis and its correlates. J Urol 1996;155:965-8.

4. Nickel JC, Nyberg LM, Hennenfent M. Research guidelines for chronic prostatitis: consensus report from the first National Institutes of Health International Prostatitis Collaborative Network. Urology 1999;54:229-33.

5. Nickel JC. Prostatitis: evolving management strategies. Urol Clin North Am 1999;26:737-51.

6. Krieger JN, Egan KJ, Ross SO, Jacobs R, Berger RE. Chronic pelvic pains represent the most prominent urogenital symptoms of "chronic prostatitis". Urology 1996;48:715-21.

7. Shoskes DA, Hakim L, Ghoniem G, Jackson CL. Long-term results of multimodal therapy for chronic prostatitis/chronic pelvic pain syndrome. J Urol 2003;169:1406-10.

8. Cho IR. The present and future of prostatitis. Korean J Urol 2008; 49:475-89.

9. Osborn DE, George NJ, Rao PN, Barnard RJ, Reading C, Marklow $\mathrm{C}$, et al. Prostatodynia: physiological characteristics and rational 
management with muscle relaxants. Br J Urol 1981;53:621-3.

10. Lacquaniti S, Destito A, Servello C, Candidi MO, Weir JM, Brisin$\mathrm{da} \mathrm{G}$, et al. Terazosine and tamsulosin in non bacterial prostatitis: a randomized placebo-controlled study. Arch Ital Urol Androl 1999; 71:283-5.

11. de la Rosette JJ, Karthaus HF, van Kerrebroeck PE, de Boo T, Debruyne FM. Research in 'prostatitis syndromes': the use of alfuzosin (a new alpha 1-receptor-blocking agent) in patients mainly presenting with micturition complaints of an irritative nature and confirmed urodynamic abnormalities. Eur Urol 1992;22:222-7.

12. Neal DE Jr, Moon TD. Use of terazosin in prostatodynia and validation of a symptom score questionnaire. Urology 1994;43:460-5.

13. Cheah PY, Liong ML, Yuen KH, Teh CL, Khor T, Yang JR, et al. Terazosin therapy for chronic prostatitis/chronic pelvic pain syndrome: a randomized, placebo controlled trial. J Urol 2003;169: 592-6.

14. Nickel JC, Narayan P, McKay J, Doyle C. Treatment of chronic prostatitis/chronic pelvic pain syndrome with tamsulosin: a randomized double blind trial. J Urol 2004;171:1594-7.

15. Mehik A, Alas P, Nickel JC, Sarpola A, Helström PJ. Alfuzosin treatment for chronic prostatitis/chronic pelvic pain syndrome: a prospective, randomized, double-blind, placebo-controlled, pilot study. Urology 2003;62:425-9.

16. Zermann D, Ishigooka M, Schubert J, Schmidt RA. Perisphincteric injection of botulinum toxin type A. A treatment option for patients with chronic prostatic pain? Eur Urol 2000;38:393-9.

17. Nickel JC, Downey J, Pontari MA, Shoskes DA, Zeitlin SI. A randomized placebo-controlled multicentre study to evaluate the safety and efficacy of finasteride for male chronic pelvic pain syndrome (category IIIA chronic nonbacterial prostatitis). BJU Int 2004;93: 991-5.

18. Persson BE, Ronquist G, Ekblom M. Ameliorative effect of allopurinol on nonbacterial prostatitis: a parallel double-blind controlled study. J Urol 1996;155:961-4.

19. Nickel JC, Forrest JB, Tomera K, Hernandez-Graulau J, Moon TD, Schaeffer AJ, et al. Pentosan polysulfate sodium therapy for men with chronic pelvic pain syndrome: a multicenter, randomized, placebo controlled study. J Urol 2005;173:1252-5.

20. Shim BS. Complementary and alternative therapy for chronic prostatitis/chronic pelvic pain syndrome. Korean J Urogenital Tract Infect Inflamm 2007;2:143-50.

21. Yang SK, Sung WS, Chung H, Kim TW, Kim HS, Lho YS. Biofeedback and functional electrical stimulation therapy for patients with intractable chronic pelvic pain syndrome. Korean J Urol 2003;44: 1220-4.

22. Cho IR. Evaluation and treatment of patients with prostatitis. Korean J Androl 2005;23:1-11.

23. Yavaşçaoğlu I, Oktay B, Simşek U, Ozyurt M. Role of ejaculation in the treatment of chronic non-bacterial prostatitis. Int J Urol 1999;6: $130-4$.

24. Blacklock NJ. Anatomical factors in prostatitis. Br J Urol 1974;46: 47-54.

25. Kim TH, Kim TH, Kim HR, Lee MK, Myung SC, Kim YS. Detection of cryptic microorganisms in patients with chronic prostatitis by multiplex polymerase chain reaction. Korean J Urol 2007;48: 304-9.

26. Nickel JC, Downey J, Johnston B, Clark J; Canadian Prostatitis Research Group. Predictors of patient response to antibiotic therapy for the chronic prostatitis/chronic pelvic pain syndrome: a prospective multicenter clinical trial. J Urol 2001;165:1539-44.

27. Youn CW, Son KC, Choi HS, Kwon DD, Park K, Ryu SB. Comparison of the efficacy of antibiotic monotherapy and antibiotic plus alpha-blocker combination therapy for patients with inflammatory chronic prostatitis/chronic pelvic pain syndrome. Korean J Urol 2008;49:72-6.

28. Nickel JC, Pontari M, Moon T, Gittelman M, Malek G, Farrington J, et al. A randomized, placebo controlled, multicenter study to evaluate the safety and efficacy of rofecoxib in the treatment of chronic nonbacterial prostatitis. J Urol 2003;169:1401-5.

29. Minnery $\mathrm{CH}$, Getzenberg RH. Benign prostatic hyperplasia cell line viability and modulation of jm-27 by doxazosin and Ibuprofen. J Urol 2005;174:375-9. 